\title{
Design the Connection Creation Bluetooth Techniques using Packet Switching
}

\author{
Nirmla Sharma, S. K. Gupta, Olfa Ben Said
}

\begin{abstract}
An existent result from the exchange is working. However, we are sharing unique practices to fast our creativity; it develops controlling partners by the people it abuts to, with our unhindered and the creation about us. Three-Way Handshake strategy has used in this paper to the connection creation method. TCP and affiliation creation strategies have recycled related to formal progress outline connection creation. Now every course utilizing parcel exchanging systems and 4-areas are generally required that is Finish (FIN) and Acknowledgment (ACK). Opening the reason for existing techniques is about used handset toward training. It is indicating an association to make in this paper. FIN exchanging has been powerful not only in refining the accounts of information correspondences, but also it might be in alluring consistency or reasonable versatility. Bluetooth rules are utilizing affiliation development for this paper.

When we share original practices and rapid our originality, we construct controlling associates by the individuals we're adjoining to, with our unrestricted and the creation about us, and through ourselves. Ordinary procedure is creating and linking among TCP client with server includes 3- phases consumer refers SYN communication; server refers communication that associations ACK used for consumer's $S Y N$ and encloses server's $S Y N$; then consumer directs ACK for server's SYN. It is named TCP Three Way Handshake. It is joining formation connectionless communication to comparative features. Difference among connectionless combine connection oriented broadcast could proceeds residence at numerous coatings of Open System Interconnection Orientation Model. TCP has connection oriented carrying protocol. UDP has connectionless protocol
\end{abstract}

Keywords: Bluetooth, connection, client, techniques and packet switching.

\section{INTRODUCTION (MAKING THE CONNECTION)}

Connection Creation Strategy has Three-way handshake the system. Straightforward Affiliation Development: Three-way handshake made up an affiliation; each plan requires coordinate Synchronization (SYN) and Acknowledge (ACK). In this technology has use in a different circumstance. Subsequently, it has a prerequisite toward must four switch correspondences to allow among plans [1].

However, it is uncouth toward alluding SYN with ACK now particular correspondences once one of a kind can link simultaneously. Therefore, now the standard courses of action activities are prevalent to connect the creations. SYNs different ACKs have coordinated to make through area together out of relevant bits (correspondence incidentally named SYN+ACK). It makes a whole of 3-proclamation and thought process connecting process is named Three-Way Handshake [2, 3].

\section{MOTIVATION ASSOCIATION FORMATION TECHNIQUES PRACTICE}

In this, a table has shown that for relating the Transmission Control Protocol (TCP) control recognizes the engine. At this table, whatever happens, used for both server and buyer completed the period. Each tuple outlines strict plan starts occurring, anything accomplishment the circumstance receipts that polite and formal toward changes. Exchange acquires events of all about periods of my method for now under Table 1.

Table 1 shows a predictable association to recognize between the client and server. Presentation 3-communications has directed throughout the procedure. Individually scheme changes after LOCKED formal over transitional conditions expecting association has recognized $[4,5]$

Table-I: TCP "Three-Way Handshake" association formation technique [5]

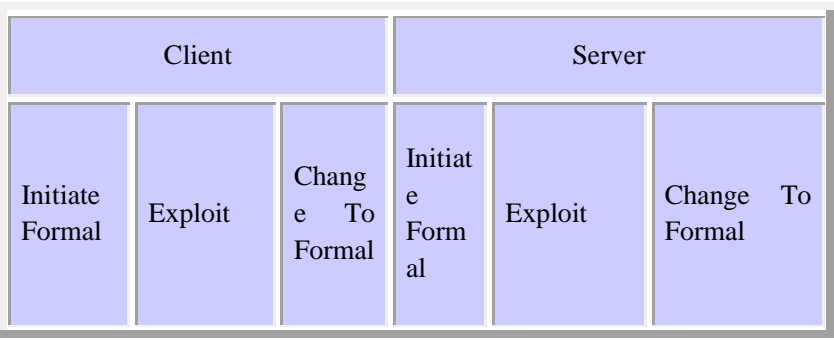

Revised Manuscript Received on February 05, 2020.

* Correspondence Author

Dr. Nirmla Sharma, Department of Computer Science, Almajardah College, Abha, Saudi Arabia. Email: nprasad@kku.edu.sa

Dr. S.K. Gupta, Department of Comp. Sc. \& Engg. BIET, Jhansi, U.P., India. Email:guptask_biet@rediffmail.com

Dr. Olfa Ben Said, Computer Science department, Almajardah college, Abha, Saudi Arabia Email: omessai@kku.edu.sa

(C) The Authors. Published by Blue Eyes Intelligence Engineering and Sciences Publication (BEIESP). This is an open access article under the CC BY-NC-ND license (http://creativecommons.org/licenses/by-nc-nd/4.0/) 
Design the Connection Creation Bluetooth techniques using Packet Switching

\begin{tabular}{|c|c|c|c|c|c|}
\hline $\begin{array}{l}\text { LOCKE } \\
\text { D }\end{array}$ & $\begin{array}{l}\text { The client } \\
\text { cannot } \\
\text { prepare. } \\
\text { Whatever } \\
\text { the server } \\
\text { has } \\
\text { achieved } \\
\text { an } \\
\text { inactive } \\
\text { OPEN an } \\
\text { d is } \\
\text { prepared } \\
\text { to receive } \\
\text { a joining. } \\
\text { (Fine, it } \\
\text { can } \\
\text { attempt, } \\
\text { but } \\
\text { nobody } \\
\text { will be } \\
\text { expert } \\
\text { until the } \\
\text { server is } \\
\text { prepared.) }\end{array}$ & - & $\begin{array}{l}\text { LOC } \\
\text { KED }\end{array}$ & $\begin{array}{l}\text { The server } \\
\text { achieves an } \\
\text { inactive O } \\
\text { PEN, } \\
\text { generating } \\
\text { a } \\
\text { transmissio } \\
\text { n control } \\
\text { block } \\
\text { (TCB) for } \\
\text { the joining } \\
\text { and } \\
\text { preparing } \\
\text { itself for } \\
\text { the } \\
\text { receiving } \\
\text { of a joining } \\
\text { request } \\
\text { (SYN) } \\
\text { after a } \\
\text { consumer. }\end{array}$ & ATTEND \\
\hline $\begin{array}{l}\text { LOCKE } \\
\text { D }\end{array}$ & $\begin{array}{l}\text { Phase \#1 } \\
\text { Transfer: } \\
\text { The } \\
\text { consumer } \\
\text { achieves a } \\
\text { dynamic } \\
\text { OPEN, } \\
\text { generatin } \\
\text { g } \\
\text { transmissi } \\
\text { on control } \\
\text { block } \\
\text { (TCB) for } \\
\text { the } \\
\text { joining } \\
\text { and } \\
\text { transfer } \\
\text { SYN com } \\
\text { municatio } \\
\text { n toward } \\
\text { the } \\
\text { server. }\end{array}$ & $\begin{array}{l}\text { SYN-S } \\
\text { ENT }\end{array}$ & $\begin{array}{l}\text { ATT } \\
\text { END }\end{array}$ & $\begin{array}{l}\text { The server } \\
\text { pauses for } \\
\text { communic } \\
\text { ation from } \\
\text { a } \\
\text { consumer. }\end{array}$ & - \\
\hline $\begin{array}{l}\text { SYN-S } \\
\text { ENT }\end{array}$ & $\begin{array}{l}\text { The } \\
\text { Client } \\
\text { pauses to } \\
\text { accept } \\
\text { an ACK t } \\
\text { o SYN it } \\
\text { has } \\
\text { directed, } \\
\text { as well as } \\
\text { server's S } \\
\text { YN. }\end{array}$ & - & $\begin{array}{l}\text { ATT } \\
\text { END }\end{array}$ & $\begin{array}{l}\text { Phase \#1 } \\
\text { Accepted, } \\
\text { Phase } \\
\text { \#2Commu } \\
\text { nicate: serv } \\
\text { er accepts } \\
\text { SYN from } \\
\text { a } \\
\text { consumer. } \\
\text { It directs } \\
\text { distinct } \\
\text { SYN+AC } \\
\text { K message } \\
\text { back to the } \\
\text { consumer } \\
\text { who covers } \\
\text { an } \\
\text { ACK for } \\
\text { the } \\
\text { client's SY } \\
\text { N, and }\end{array}$ & $\begin{array}{l}\text { SYN-RECEI } \\
\text { VED }\end{array}$ \\
\hline
\end{tabular}

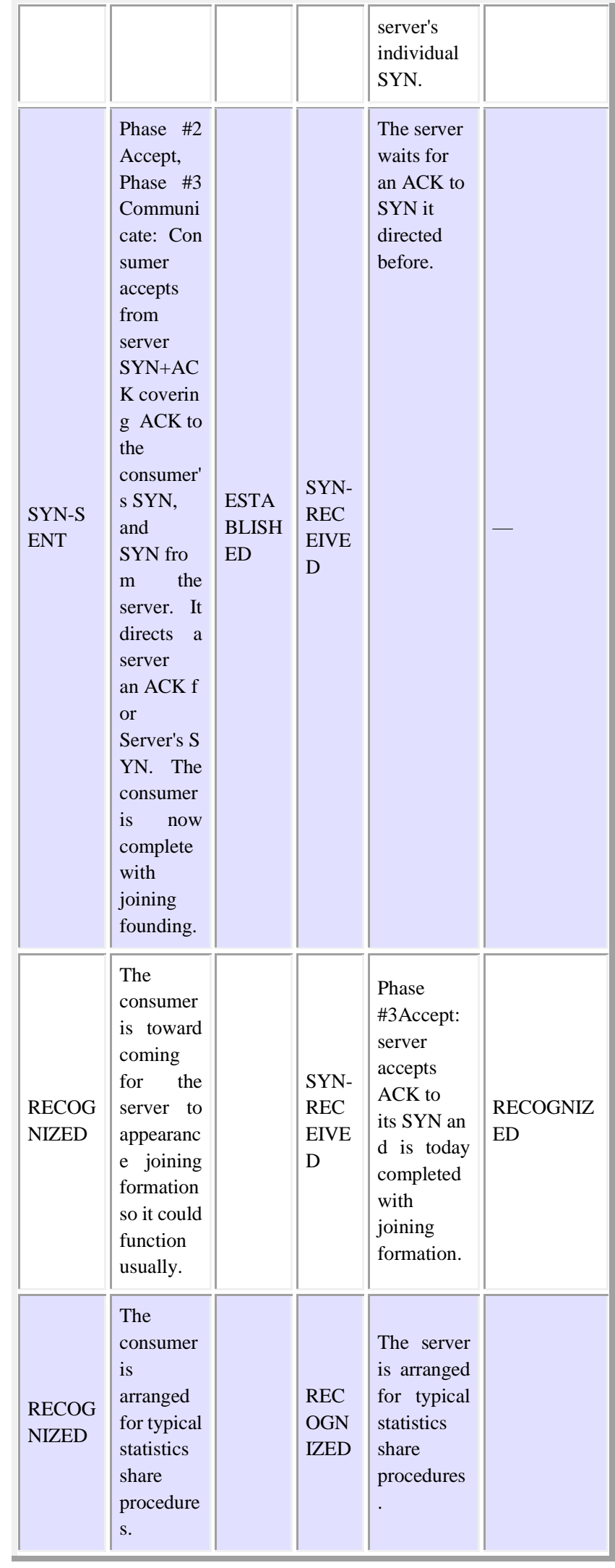

III. PROBLEM STATEMENT

The trial results of the problems have surveyed the Web Services security evaluation unit. Introduction demonstrates with various timestamp definitions in the examination errors have portrayed.

Published By:

Blue Eyes Intelligence Engineering 
The proving characterized has been extra activities powers and experiments situation.

At that point, the unit characterized the general evaluation show with the whole the web benefit arrangement containing Portable Host and the customer. Extra the section ends with the trial results and execution examination of the Portable Host. Real synchronization focuses appropriately on the correspondence to run trades. They are security areas to enhance the actualities from at least one minor manage has classified for removing the error when a mistake happens [6].

\section{METHODOLOGY (TCP ASSOCIATION CREATION AND FINISH ASSOCIATION)}

\section{A. Design the Association Creation}

Though it leads sections 3 toward creating an association, it completes precedes 4 toward remove.

- The request has requirement nearby primary approximately. It finishes completes dynamic the adjacent. Finishes TCP direct FIN section, which resources it has completed the transfer facts.

- The inactive close process has accepted FIN. Established FIN has recognized through TCP. Acceptance of FIN has been received to ask the till of end-of-file (afterwards, the request might have before remained line up for some facts to accept). Former receives of FIN resources requested cannot agree before some extra facts organized an association.

- One-time the future asks establishes end-of-file would close its socket. TCP association shows direct FIN communication.

- TCP needs an organization.

- Call accepts its last FIN (finish that fixed dynamic adjacent) recognizes FIN.

$$
\text { Client Server }
$$

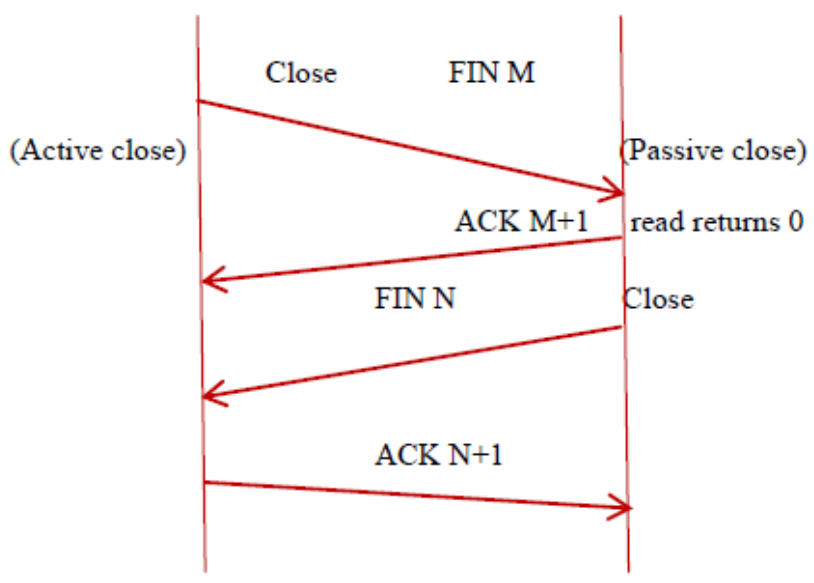

Fig1. Packets switched once a TCP association is locked [8]

FIN consolidated ACK is important every freeway for 4-segments generally simple. It rehearses the finalist "for the most part" since, in specific circumstances; FIN in Stage 1 has coordinated through certainties. Essentially, areas famous Stages 2 and 3 are one after the complete execution inert, close and may stay shared into one segment. It shows these packets in above figure 1 . FIN possesses the extraordinary byte of request universe goal comparative SYN. ACK of each FIN is a structured measure of FIN attractive one of a kind.

\section{B. Three-Way Handshake}

There are three phases of TCP Association below. This, the strategy has happened once TCP affiliation perceives: The server can stay ready for getting an internal affiliation. It has typically finished through exertion outlet, ties, and goes to title an inert uncovered.

A consumer acknowledges the server's SYN. At least amount of the packets necessary has used for conversation three. Therefore, it has titled TCP's Three-Way Handshake . It has shown of three sections in below figure 2 [8].

$$
\text { Client Server }
$$

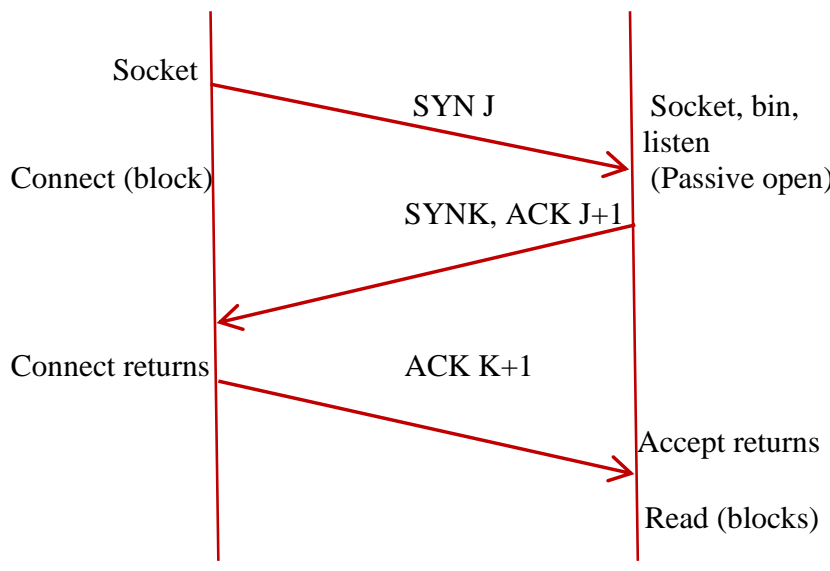

Fig2. TCP Three-Way Handshakes [8]

\section{TCP Selections}

Every SYN can cover TCP selections. Usually, recycled decisions contain succeeding:

- Mobile Servicing System (MSS) decision: Through its decision, TCP is pointing SYN broadcasts regular section extent. The full volume of figures is prepared to receive the common every TCP section programmed its association. The request is sending TCP procedure's headset's MSS worth by way of the determined extent that it directs. It would understand in what way toward realizing and usual this TCP selection with TCP_MAXSEG opening selection.

- Frame measure decision: The perfect frame could present TCP 65,535 since trust packets TCP title dependent sixteen bits.

- Time-stamp decision: The decision has desired for general rapidity associates to stop probable statistic's exploitation produced too strong, late or repeat sections. Meanwhile, it is a fresher decision; this has transferred, likewise, toward frame measure choice $[8,9]$.

\section{RESULT AND DISCSSION}

\section{TCP Protocol (State Transition Diagram)}

The strategy of TCP toward affiliation creation joins complete attachment could relate to stating progress chart.

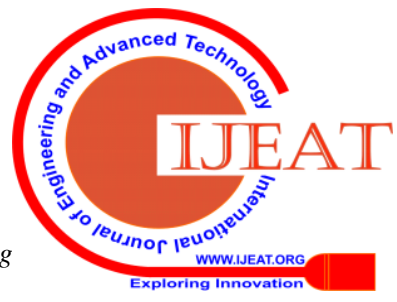




\section{Design the Connection Creation Bluetooth techniques using Packet Switching}

It has even different circumstance particular to use affiliation and bearings of TCP arrange changes important side toward established present condition and segment built up in the process. For example, vulnerability asked for accomplishes dynamic uncovered in secured condition TCP coordinates an SYN singular state is SYN_DIRECTED.

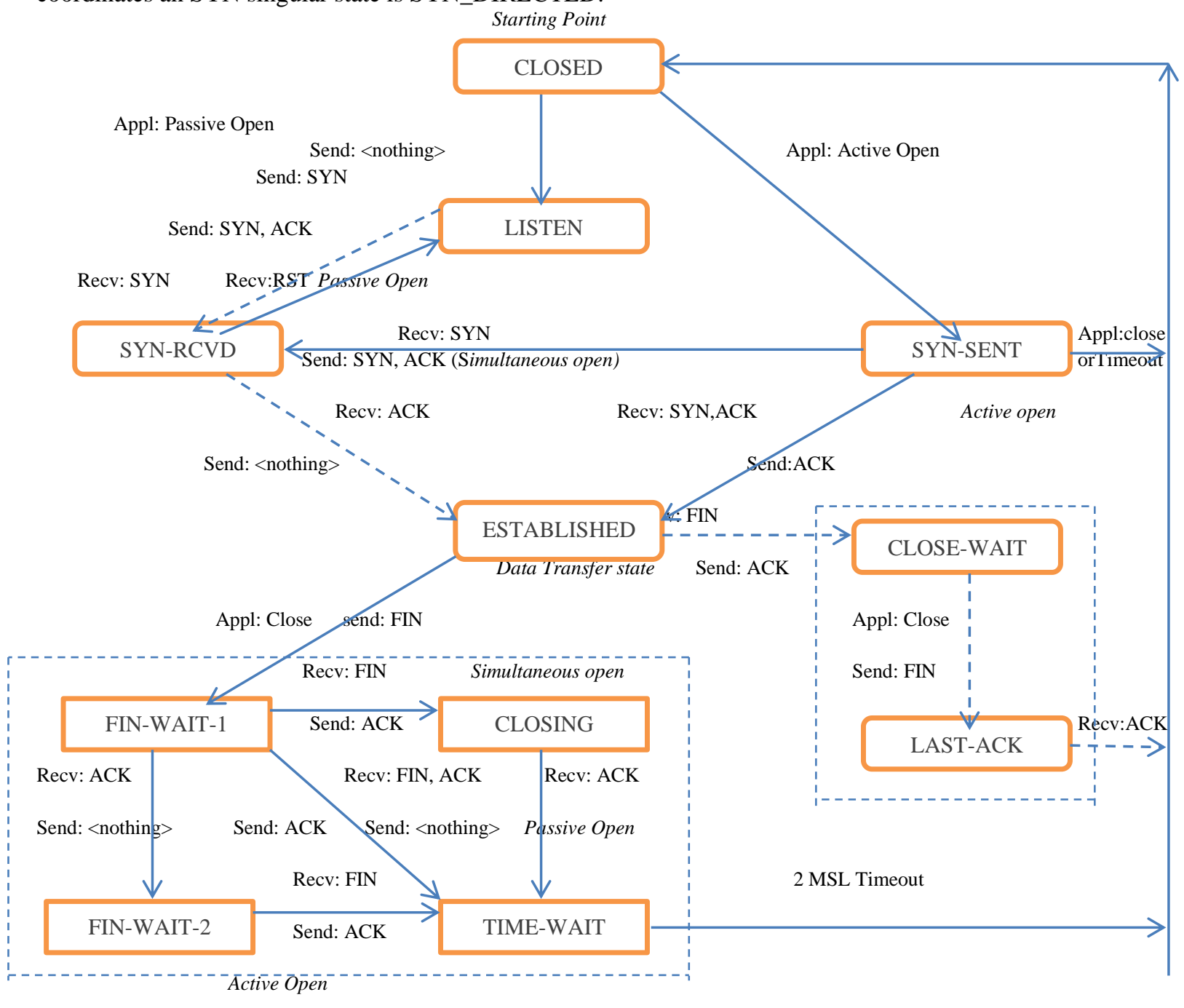

$\longrightarrow \quad$ Indicate Normal Transition for client

$--->\quad$ Indicate Normal Transition for sever

Appl: Indicate state transition taken when application issues operations

Recv: Indicate state transition taken when segments received

Send: Indicate state sent for this transition

Fig3. TCP State Transition Diagram [9]

The vulnerability TCP following acknowledges SYN and ACK; it coordinates ACK, and the unique state has perceived. Closure state is occurred to place the most remarkable certainty's task. Two ways rocket vital after perceived state contract through complete with affiliation. Vulnerability demands to calls close to getting balance (a dynamic close) toward changing the FIN_WAIT_1 state. Vulnerability asks for acknowledging a balance. However, in perceived express (an inert nearby), change is toward CLOSE_WAIT state. It tells to standard buyer changes, through the dimmer hard-line and customary server has changed of dimmer surged stripe. It later closes by remains two changes that it does not impart close concurrent opened [7]. Once together completes to coordinate SYN at around a comparable period and SYN cross in the framework show in table 2 and 3.
Published By:

Blue Eyes Intelligence Engineering
Blue Eyes Intell 
Table-II: Packets switched with TCP association is locked [8]

\begin{tabular}{|l|l|l|l|}
\hline Client & Server & SYN-RCVD & SYN-SENT \\
\hline Active Close & Passive Close & Recv: ACK & Send: ACK \\
\hline Close & FIN M & Send:FIN & Recv: FIN \\
\hline ACK M+1 & Return & $\begin{array}{l}\text { TCP association } \\
\text { is locked }\end{array}$ & $\begin{array}{l}\text { TCP } \\
\text { association is } \\
\text { listen }\end{array}$ \\
\hline FIN N & Close & Recv: FIN & Send: FIN \\
\hline Close & ACK N+1 & Close-Wait & Last- ACK \\
\hline
\end{tabular}

Table-III: TCP Three-Way Handshakes [8]

\begin{tabular}{|l|l|l|l|}
\hline Client & Server & SYN-RCVD & Listen \\
\hline $\begin{array}{l}\text { Socket } \\
\text { Connect }\end{array}$ & Socket Listen & Recv: SYN & Recv:RST \\
\hline SYN J & $\begin{array}{l}\text { SYNK, ACK } \\
\text { J+1 }\end{array}$ & FIN-Wait-1 & Close \\
\hline $\begin{array}{l}\text { Connect } \\
\text { returns }\end{array}$ & ACK K+1 & FIN-Wait-2 & Time-Wait \\
\hline Read block & Accept returns & Recv: FIN & Send: ACK \\
\hline
\end{tabular}

The simultaneous process completes coordinating FIN at the unclear period. TCP covers cases and discussion of together circumstances, which are likely than incidental. We show the state transition condition above figure $3[9,10]$.

\section{CONCLUSION}

For the most part, together is not coordinate at all certainties through SYN; it has determinations targeted cover's IP header, TCP goal, and likely TCP (which it can conversation around presently). The server must recognize (ACK) buyer's SYN, and the server must additionally coordinate its individual SYN covering the unique course of action sum for insights that the server would coordinate on connecting. The server synchronizes SYN and ACK of customer's SYN specifically segment. The unit characterized the general evaluation show with the whole the web benefit arrangement containing Portable Host and the customer. Extra the part closes with trial results and execution examination of the Versatile Host.

The synchronization which has exhibited circumstances focuses on the information control stream and errors in the session layer. Synchronization focuses to convey a communication into a grouping of trade. Synchronization has observed before the session to manage. At the point when any mistake happens figures have improved active to the previous key. Synchronization has targeted indicators to bring the focal of skill communication.

\section{FUTURE WORK}

It could not be refined once Asynchronous Connectionless Link (ACL) to affiliate. It has achieved the person once an application to examination conceded. It can experiment now together demands: the client affirms server and pivot process. They prohibitive on the requesting may perhaps need a certificate. They are security areas to enhance the actualities from at least one noteworthy and minor synchronization focuses inside an entomb change when a mistake occurs. It is absent extra examinations to introduce the TCP, ACK, and SYN when Bluetooth Systems communicate to use for around the world.

\section{REFERENCES}

1. Hsu Fu-Hau, et al. TRAP: A Three-Way Handshake Server for TCP Connection Establishment. Application Science 2016; 6: 358-372. doi:10.3390/app6110358 http://www.mdpi.com/journal/applsci.

2. Parashar Ankush, Kakka Parveen. Defence against SYN Flooding Attacks based on Swarm Intelligent Ant Colony Optimization Technique. International Journal of Computer Science \& Communication March-Sept 2018; 9: 19-27.

3. Geetha K, Sreenath N. Detection of SYN Flooding Attack in Mobile Ad-hoc Networks with AODV Protocol. Springer: Arabian Journal for Science and Engineering 2016; 41: 1161- 72.

4. Johansson N, Kihl M, Korner U. TCP/IP over a Bluetooth wireless ad-hoc network. In: Proc. IFIP Networking 2000: 1999; Paris. pp. 799-810.

5. Beardsley Tod, Qian Jin. The TCP Split Handshake: Practical Effects on Modern Network Equipment. Network Protocols and Algorithms. 2010; 2: 197-217.

6. Duane G S. Synchronicity from synchronized chaos. Entropy 2015; 17: 1701-1733.

7. Miao L, Ding W, Gong J. A real-time method for detecting internet-wide SYN flooding attacks. In Proceedings of the IEEE International Workshop Local and Metropolitan Area Networks (LANMAN); 22-24 April 2015; Beijing, China. pp. 1-6.

8. Lemon J. Resisting SYN Flood DoS Attacks with an SYN Cache. In Proceedings of the BSD Conference 2002 on BSD Conference; 15-17 November 2002; Amsterdam, Netherlands. pp. 89-97.

9. Jin H, Tang D, Zhang Y, Chen H. SHAK: Eliminating faked three-way handshaking in socket handoff. In Proceedings of the 18th International Parallel and Distributed Processing Symposium; 26-30 April 2004; Santa Fe, Mexico. pp. 184-198.

10. $\mathrm{Wu} \mathrm{Z}$, Chen $\mathrm{Z}$. A three-layer defence mechanism based on web servers against distributed denial of service attacks. In Proceedings of the First International Conference on Communications and Networking in China; 25-27 October 2006; Beijing, China. pp. 1-5.

\section{AUTHORS PROFILE}

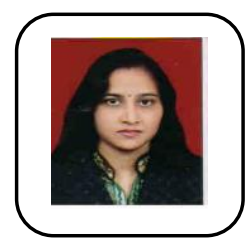

Profile Dr. Nirmla Sharma, $\mathrm{PhD}$ from Teerthanker Mahaveer University Muradabad, U.P., INDIA. Currently working in King Khalid University Abha, Saudi Arabia as Asst. Prof department of computer science. Initially Graduating from CCS University Meerut U.P. INDIA and then Master in Computer science from Rajasthan Vediyapeeth Rajasthan And then M.Tech I.T. From Vinayak Mission University, Tamil Nadu. And MCA from IGNOU New Delhi Published 14 Paper in International Journals, 03 in National Journals, 07 National Conferences, attended 11 International Conference 08 National Workshops/Conferences. Other responsibilities i.e. Head, Dept. Of CSE and Time Table Convener at AIT, Ghaziabad, INDIA Head Examiner, for different subjects of C.S. and I.T. in Central Evaluation of M.T.U.NOIDA /U.P.T.U., Lucknow, U.P. Paper Setter/Practical Examiner in different Institutes/Universities time to time i.e. CCSU Meerut/UPTU, Lucknow.

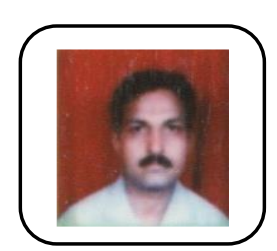

Profile Dr. S. K. Gupta, Presently working as A.P. in Comp. Sc. \& Engg. Deptt. of BIET, Jhansi, U.P. INDIA. Currently on deputation by State Govt. at Mahamaya Technical University (MTU), Noida, U.P., INDIA as Joint Controller Of Examination. Initially graduating in Computer Science \& Engineering from H.B.T.I., Kanpur, U.P., INDIA and then M.E. from M.N.R.E.C., Allahabad, U.P., INDIA and after that completed Ph.D. in Computer Science \& Engineering from Bundelkhand University, Jhansi, U.P., INDIA. 


\section{Design the Connection Creation Bluetooth techniques using Packet Switching}

05 Ph.D.'s are going on. 04 M.Tech. thesis and 40 B.Tech. /M.C.A. projects supervised. Published 06 Paper in International Journals, 01 in International Conference, 06 in National Conferences, attended 01 International Conference, 01 Winter School, 06 STTP, 09 International/National Workshops/Conferences. Other responsibilities i.e. Head, Deptt. Of I.T. at BIET, Jhansi, Head Examiner, for different subjects of C.S. and I.T. in Central Evaluation of U.P.T.U., Lucknow, U.P. Member of Inspection Committees, constituted by UPTU, Lucknow for approval of New Institutions/Courses/Extension of Approval/Seats time to time. Member of Board of Studies/Paper Setter/Practical Examiner in different Institutes/Universities time to time

i.e. UPTU, Lucknow, RGPV, Bhopal, M.P., Jivaji University, Gwalior, M.P., MGCGV, Chitrakoot, M.P., B.U., Jhansi, Jaypee Institute, Guna, M.P., MITS, Gwalior, M.P. etc. Approved Counsellor/Project Evaluator of I.G.N.O.U. for M.C.A. and B.C.A. courses.

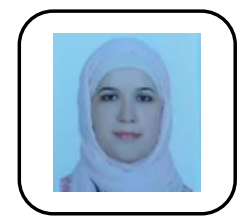

Profile Dr. Olfa Ben Said, $\mathrm{PhD}$ on computer sciences from ENIS, University of Sfax, Tunisia. Currently working in King Khalid University Abha, Saudi Arabia as Asst. Prof department of computer science. Initially She received her bachelor degrees in computer sciences in FSS, Sfax Tunisia. Then she obtained the master from ENIS, University of Sfax, Tunisia . Published 1 Paper in International Journals, 4 International Conferences and . attended some National Workshops/Conferences. Project supervisor Developing E-learning school system to improve learning outcome, another project Guide Recruitment System. Subject are taught Multimedia, Artificial Intelligent Database, Compiler design, Introduction to Web Technology etc. and Examination controller. 